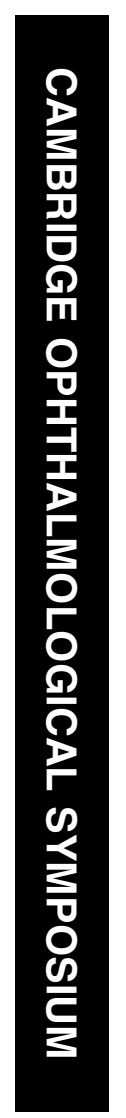

\section{Intraocular surgery for optic nerve disorders}

\begin{abstract}
This article discusses two current indications for intraocular surgery for optic nerve conditions. The first topic is macular detachment in association with congenital optic disc pit, and includes a review of the theories of pathogenesis and management options including our own experience of treatment with vitrectomy and gas tamponade. In addition, the histopathological findings of a new case of optic disc pit with serous macular detachment are presented, adding to the rare examples previously reported. The second subject is a radial optic neurotomy, a recently advocated treatment for central retinal vein occlusion, which, despite its controversial nature, is gaining in popularity.
\end{abstract}

Eye (2004) 18, 1056-1065. doi:10.1038/sj.eye.6701572

Keywords: optic nerve; macula lutea;

${ }^{1}$ Vitreoretinal Service Addenbrooke's NHS Trust Cambridge, UK

${ }^{2}$ Department of Pathology University Hospitals Coventry and Warwickshire NHS Trust, Coventry, UK

\section{${ }^{3}$ Department of}

Ophthalmology, York Hospitals NHS Trust, York UK

Correspondence: A Poulson Vitreoretinal Service, Box 41 Addenbrooke's NHS Trust Hills Road

Cambridge

CB2 2QQ, UK

Tel: + 441223216701

Fax: +441223217968.

E-mail: arabellapoulson@ ntlworld.com

Received: 4 September 2003

Accepted: 4 September 2003 vitrectomy; retinal vein occlusion

Optic disc pit and serous macular detachment

Optic pits were first described in both optic

discs of a 62-year-old woman in 1882 by Wiethe. ${ }^{1}$ They are congenital defects within the optic nerve head and appear as grey dimples usually just within the disc margin (Figure 1). They vary in size but on average are width. ${ }^{2}$ Pits are usually single but can be multiple and may be bilateral in $10-15 \% .^{3}$ In $80 \%$ the disc is symmetrically enlarged ${ }^{4}$ and in over $60 \%$ cilioretinal vessels are found traversing the pit. $^{5}$ The majority occur in the temporal side of the optic disc with adjacent peripapillary retinal pigment epithelial changes. Optic disc pits occur in approximately 1:11 $000^{6}$ and occur equally in either sex.

There is controversy over their pathogenesis. Gass suggests that because pits occur more frequently on the temporal rather than the nasal side of the disc, they are primarily related to approximately a third of a disc-diameter in
AV Poulson ${ }^{1}$, DRJ Snead ${ }^{2}$, PM Jacobs ${ }^{3}$, N Ahmad $^{1}$ and MP Snead ${ }^{1}$

anomalous development of the primordial optic nerve papilla and failure of complete resolution of peripapillary neuroectodermal folds ${ }^{7}$ rather than being true colobomata. Sugar $^{8}$ argues that they may be caused by incomplete closure of an abnormally located, twisted, or shifted embryonic fissure. Optic disc pit, morning glory syndrome, and coloboma of the optic nerve have all been seen in a five-generation pedigree of 35 members, inherited in an autosomal dominant pattern. ${ }^{9}$ Apple and $\mathrm{Rabb}^{2}$ have emphasised that because the normal fissure completely surrounds and encompasses the developing optic disc, it would seem reasonable to consider an optic pit lesion as another form of typical coloboma.

PAX2 gene mutations have been found in the renal-coloboma syndrome, which is a rare autosomal dominant syndrome that causes optic nerve colobomata and renal hypoplasia. Optic disc pits have been described as part of this syndrome. Unilateral optic pits may be inherited in an autosomal dominant manner but are not associated with mutations in the PAX2 gene. $^{10}$

\section{Visual fields}

The visual field defects found with pits are most commonly large blind spots. ${ }^{11}$ Arcuate scotomata probably reflect the absence of a wedge of nerve fibres displaced by the optic disc pit. Larger pits may be associated with altitudinal visual field defects. When a macular detachment occurs, further visual field loss is superimposed on that already produced by the nerve fibre layer defect.

\section{Serous macular detachment}

Patients with congenital optic disc pits may develop a serous detachment of the macula (Figure 2). This usually develops between the ages of 20 and 40 years, but can occur at any 


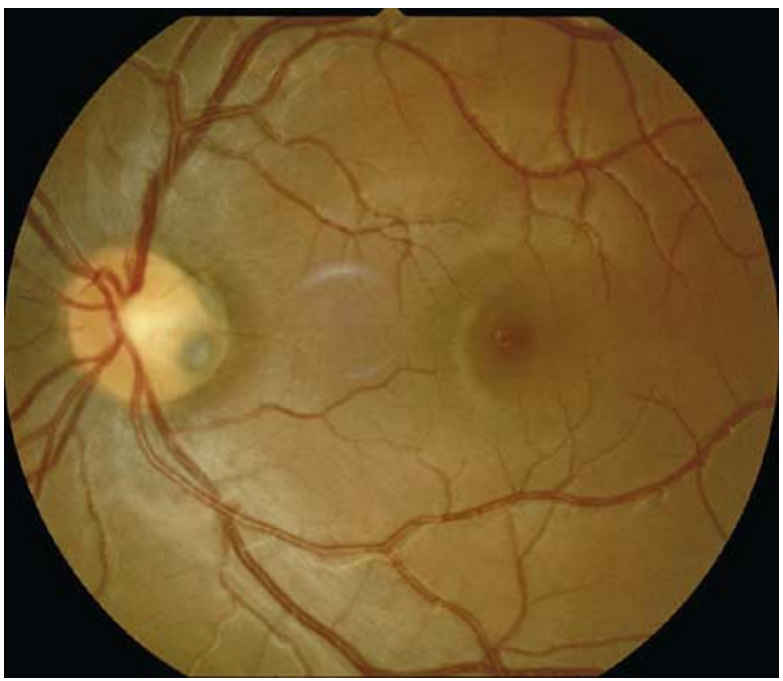

Figure 1 Left fundus of a 11-year-old girl with an optic disc pit.

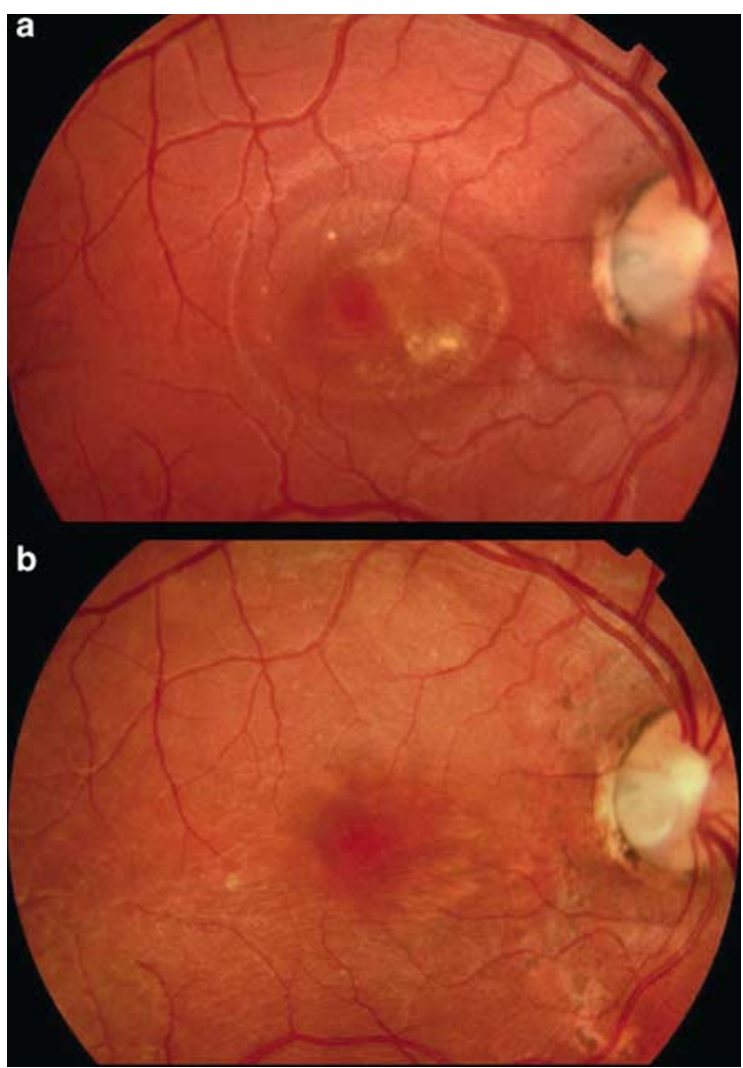

Figure 2 Right fundus of a 19-year-old woman with a visual acuity reduced to $6 / 36$ due to a serous macular detachment associated with an optic disc pit (a) and attached macula following vitrectomy, photocoagulation and gas, with a final visual acuity of $6 / 12(b)$.

age, and extends from the optic disc margin adjacent to the pit. In 1908, Reis first described a case of an optic nerve pit with associated maculopathy. ${ }^{2}$ In 1960,
Kranenburg $^{6}$ reported 24 cases of pits in the optic disc and observed a picture of central serous retinopathy in $30 \%$; and in another $20 \%$ evidence of a previous episode. Sugar $^{8}$ found that macular lesions have been described in $32 \%$ of 157 reported cases of optic disc pit. Long-standing serous retinal detachment can eventually lead to cystic degeneration of the macula and loss of pigment from the underlying retinal pigment epithelium. Lamellar and, rarely, full-thickness macular hole may develop. Occasionally, there may be a cloudy precipitate on the posterior surface of the detached retina, which may be misdiagnosed as a solid tumour. ${ }^{12}$

Some patients develop a surrounding elevation of the inner retinal layer suggestive of a retinoschisis. Lincoff $e a^{13}$ proposed that fluid emanating from the pit created a schisis-like separation of the inner layers of the retina and, furthermore, that detachment of the outer layers from the retinal pigment epithelium was a secondary process occurring at the macula. They do not exclude the possibility of a previous episode of macular detachment as the explanation for schisis. Gass ${ }^{12}$ suggests that this is not a true retinoschisis because there is not complete loss of retinal function.

\section{Angiography}

In early phases of fluorescein angiography, the optic pit appears hypofluorescent, with late staining of the pit in most cases. Late staining is more likely to be present in long-standing macular detachment and where a cilioretinal artery is associated with the pit. ${ }^{14}$ Absolute hypofluorescence of the optic disc pit occurs with indocyanine green angiography. ${ }^{15}$ Fluorescein angiography usually shows no leakage of dye into the subretinal fluid in those with serous macular detachment. ${ }^{12}$ However, Theodossiadis et al ${ }^{15}$ recently described late hyperfluorescence corresponding to the area of macular elevation in all 17 studied eyes on both indocyanine green and fluorescein angiography. Patchy late hyperfluorescence due to depigmentation of the retinal pigment epithelium may be seen in long-standing retinal detachment. Fluorescein angiography shows no evidence of either choroidal or retinal vascular permeability changes.

\section{Natural history}

Brown et $a l^{4}$ followed 20 patients with untreated macular detachments associated with optic disc pit for more than a year and found that $55 \%$ had visual acuities of $6 / 30$ or worse and $75 \%$ had persistent subretinal fluid. Sobol et al $^{16}$ followed 15 patients with a serous macular detachment arising from an optic disc pit, for an average 
of 9 years and found that $80 \%$ had a visual acuity of 20 / 200 or less. It was also noted that the visual loss occurred during the first 6 months of observation.

Theodossiadis et $a l^{14}$ watched 16 patients with persistent macular detachment for an average of 9.5 years: eight patients were unsuccessfully treated with laser photocoagulation adjacent to the temporal margin of the disc and the other eight were not treated. Final visual acuity was less than 20/200 in all cases.

\section{Pathogenesis of macular detachment}

There is no reason to doubt that the serous macular detachment in eyes with pits is causally related to pit. The origin of the subretinal fluid, however, remains controversial and several sources have been proposed, including vascular, vitreous, and cerebrospinal fluid.

There is general agreement that because fluorescein angiography shows no leakage from either choroidal or retinal circulations or from vessels within the pit itself, ${ }^{7}$ a vascular source is unlikely.

Sugar postulated that fluid may leak from the vitreous cavity through the pit into the subretinal space ${ }^{17}$ and his theory has been supported by others. $2,18,19$

Postel et $a l^{20}$ reviewed the records of seven cases of serous macular detachment associated with optic pits or related cavitary anomalies, identified an apparent defect in the diaphanous tissue overlying the optic nerve pit and felt this to be responsible for the development of serous macular detachment. None of the patients had a posterior vitreous detachment.

Bonnet $^{21}$ observed a small hole in the roof of the optic pit in several cases and small bubbles of gas passing from the vitreous cavity to the subretinal space via the optic disc pit in a case that underwent vitrectomy and gas tamponade. Bonnet concluded that macular detachments in optic disc pits have a rhegmatogenous component at the optic disc associated with vitreous traction and that the subretinal fluid comes from the vitreous space via the optic disc pit. The presence of condensed vitreous strands has led Billi et $a l^{22}$ to propose a possible tractional role of anomalous vitreous adhesion.

Macular detachments generally occur in patients too young to have significantly liquefied vitreous and most authors agree that patients do not have a posterior vitreous detachment.

Communication between the vitreous cavity and the subretinal space via the optic pit has been demonstrated in collie dogs ${ }^{23}$ but not in humans.

Lincoff and Kreissig ${ }^{24}$ used optical coherence tomography (OCT) to image the eyes of three patients with optic disc maculopathy and demonstrated a schisislike cavity connecting to the pit in each case. They concluded that persistence of fluid, despite gas tamponade of the optic pit and macula, makes it unlikely that retinal breaks at the edge of the disc are transferring fluid from the vitreous to beneath the retina.

Irvine $e t a l^{25}$ described optic nerve sheath fenestration in a previously vitrectomised eye with morning glory disc and retinal detachment, and observed gas from the fluid-gas exchange bubbling through the nerve fenestration, demonstrating continuity of the vitreous cavity with the perineural space. The authors suggest that the porous nature of the poorly differentiated tissue herniated around the optic nerve into the subarachnoid space in morning glory disc and optic pit makes several sources of subretinal fluid possible.

Regenbogen et $a l^{26}$ and Gass ${ }^{7}$ proposed the idea that subretinal fluid could be derived from cerebrospinal fluid. Krivoy et $a l^{27}$ used OCT to image three eyes with optic disc pit and serous macular detachment demonstrating a communication between either a schisis cavity, or subretinal space, and the optic nerve pit in all eyes. A direct communication between the subretinal space and vitreous cavity could not be identified in any eye arguing in favour of the cerebrospinal fluid theory.

Kalina and Conrad ${ }^{28}$ injected fluorescein intrathecally in an attempt to reveal a subarachnoid-subretinal fistula. Unfortunately, the patient suffered anaesthesia and paralysis of the lower limbs after only a very small amount of fluorescein had been injected. Failure to identify fluorescein in the subretinal fluid in this situation did not exclude cerebrospinal fluid as the source. Savell and $\mathrm{Cook}^{29}$ used radioisotope cisternography but could not demonstrate radioactivity of the subretinal fluid. One patient with an optic disc pit experienced two episodes of raised intracranial pressure caused by idiopathic intracranial hypertension and did not develop retinal detachment. ${ }^{7}$

There is evidence that there is normally no barrier to molecular movement at the surface of the optic disc, so simple hydrostatic forces could cause a fluid movement from the vitreous cavity through the nerve head to the subarachnoid space, normal intraocular pressure being higher than optic nerve tissue pressure. ${ }^{11}$ Movement of fluid into the subretinal space in the presence of an optic disc pit may be the result of a deficiency of tight junctions that are normally present between cells lining the termination of the retina and pigment epithelial layers at the optic nerve head. ${ }^{30}$

\section{Treatment}

Spontaneous resolution of the macular detachment is reported to occur in up to $25 \%$ of cases, ${ }^{12}$ although permanent visual loss may ensue if the macular detachment is prolonged or recurrent. The poor visual 
outcome in natural history studies has prompted the search for an acceptable treatment.

Montenegro and Bonnet ${ }^{31}$ found that the serous macular detachment did not respond to systemic corticosteroids used in five patients.

Reattachment of the retina has been reported in one patient following optic nerve sheath decompression. ${ }^{32}$

In 1966, Gass ${ }^{7}$ applied laser photocoagulation along the temporal margin of the disc and within the pit but with no resolution of the subretinal fluid. Brockhurst ${ }^{18}$ reported six cases treated with photocoagulation along the disc margin in the area of retinal detachment. In five the retina was reattached after the clinical development of a firm chorioretinal adhesion at the disc margin, and the sixth appeared to improve spontaneously. Subretinal fluid resolved after krypton laser therapy in four of five patients treated by Annesley et al. ${ }^{33}$ Cox et al ${ }^{34}$ found photocoagulation of the temporal disc border alone was unsuccessful in two cases but promptly reattached the macula of a further two patients immobilised after laser surgery. Theodossiadis et $a l^{14}$ treated eight patients with laser and none was successful. Monin et $a l^{35}$ found that of a group of six eyes treated by laser alone, only two were successful; in three the detachment recurred and were successfully treated with intraocular gas injection.

Lincoff and Kreissig ${ }^{24}$ used pneumatic displacement without photocoagulation to treat 12 eyes. There was an initial visual improvement coinciding with flattening of the macula in nine, but with late recurrence. It was believed that the schisis-like nature of the inner leaf separation, which resisted gas compression, also explained the frequent failure of laser photocoagulation. Other investigators report variable success using pneumatic displacement combined with photocoagulation $^{31,21,36,35}$ and suggest that the use of perfluoropropane as a tamponade seems to be superior to sulphur hexafluoride.

Alexander and Billson ${ }^{37}$ reported two patients successfully treated with vitrectomy and gas tamponade combined with photocoagulation. Cox et al ${ }^{34}$ reported prompt and sustained macular reattachment, with improved vision, after photocoagulation, vitrectomy, and gas tamponade in eight patients, although four required second operations. There have been numerous reports of treatment with vitrectomy, laser, and gas, ,3,35,38-42 $^{\text {some }}$ advocating removal of the posterior hyaloid or inner limiting membrane; ${ }^{43-46}$ and one the use of autologous platelets. $^{47}$

One centre treated nine consecutive patients with a macular buckling procedure. ${ }^{48}$ A large scleral sponge was fixed vertically at the posterior pole over the macula and localised using B-scan ultrasonography. No retinopexy was used. In all eyes, there was resolution of the subretinal and intraretinal fluid with no recurrence over a mean follow-up of 42 months. Six eyes gained four or five lines of visual acuity, and two eyes improved by three lines.

The authors' experience in managing macular detachment associated with optic disc pit is summarised in Table 1.

In none of the patients was a posterior vitreous detachment present, nor was there a suggestion of a schisis or pseudoschisis. In those who underwent surgery, it was not possible to drain the fluid internally via the optic disc pit during vitrectomy, suggesting that there was no rhegmatogenous element. The fluid was displaced inferiorly by the gas, where it remained localised for a few weeks before eventually disappearing.

The management of macular detachment associated with optic disc pit has evolved over the last two decades and most series have consequently included a variety of different techniques, employed usually after prolonged macular detachment. It is not easy to predict the most appropriate or effective treatment, but it would be logical to conclude that the limited recovery in visual acuity could be improved by successful early reattachment.

Gass $^{12}$ recommends observation for at least a month after the onset of the detachment; if no response occurs within 6-8 weeks, repeat laser treatment is advised. Intravitreal gas tamponade with or without pars plana vitrectomy should be considered if no improvement in the detachment occurs.

Table 1 Summary of the management of six patients with optic disc pit and serous macular oedema

\begin{tabular}{|c|c|c|c|c|c|c|c|}
\hline Case & $\begin{array}{c}\text { Age } \\
\text { (years) }\end{array}$ & Sex & Initial VA & Treatment & Anatomic outcome & Final VA & $\begin{array}{l}\text { Length of } \\
\text { follow-up } \\
\text { (months) }\end{array}$ \\
\hline 1 & 20 & $\mathrm{~F}$ & $6 / 18$ & Vitrectomy + laser + gas & Attached & $6 / 9$ & 6 \\
\hline 2 & 9 & M & $6 / 60$ & Vitrectomy + laser + gas & Attached & $3 / 60$ & 29 \\
\hline 3 & 27 & $\mathrm{~F}$ & $\mathrm{CF}$ & Vitrectomy + laser + gas $\times 2$ & Attached & $6 / 18$ & 30 \\
\hline 4 & 16 & $\mathrm{M}$ & $6 / 18$ & Observation & Attached & $6 / 18$ & 24 \\
\hline 5 & 19 & $\mathrm{~F}$ & $6 / 36$ & Vitrectomy + laser + gas & Attached & $6 / 12$ & 2 \\
\hline 6 & 34 & M & $6 / 24$ & Observation & Detached & Patient died from septicaemia & \\
\hline
\end{tabular}




\section{Histopathology}

Histopathological specimens of optic disc pit associated with macular detachment are rare. Gass7 reviewed the histopathology of two eyes previously reported by Ferry. ${ }^{49}$ Both were removed with the incorrect clinical diagnosis of malignant melanoma of the choroid. The optic pit consisted of herniation of dysplastic retina into a collagen-lined pocket extending posteriorly through a defect in the lamina cribrosa into the subarachnoid space. In contrast to optic disc pits in collie dogs, where vitreous has been shown to enter the pit, none was demonstrated within the pit or in the subretinal space. He felt that cerebrospinal fluid might gain entrance to the subretinal space more easily than vitreous as it did not require passage through an epithelial barrier.

Case 6 (Table 1) was a 34-year-old man who presented with right central visual loss and an orange after-image due to an optic disc pit with a serous macular detachment (Figure 3). Unfortunately, he died from septicaemia of unknown cause some months later. His eyes were retrieved after consent from his next-of-kin, providing the opportunity for histopathological examination.

The globes were removed several days after death and fixed in formalin for a further 48 hours, causing shrinkage of the globes and artefactual retinal detachments. Serial sections of the right globe showed a flask-shaped pit lying at the inferior margin of optic disc adjacent to the lamina cribrosa, and communicating directly with the subretinal space (Figure 4). There were no vascular abnormalities or remnants of the hyaloid artery. The vitreous was normal and the posterior hyaloid membrane remained attached. Although it is difficult to be certain, there was no evidence of a retinoschisis. There were ectopic remnants of retinal pigment epithelium within the pit cavity. The intervening connective tissue between the subarachnoid space and the pit was very thin. Although there was no direct connection between the two, it may be possible that cerebrospinal fluid could transudate across the collagen to the pit.

\section{Conclusions}

In summary, there is no conclusive evidence as to the aetiology of the subretinal fluid in optic disc pit maculopathy. It seems plausible that it comes from cerebrospinal fluid, and this is supported by histological studies demonstrating close proximity of the subarachnoid space and the pit, and OCT showing communication between the pit and macular fluid, together with the failure to show a direct communication between the vitreous and pit, either histologically or peroperatively while attempting to aspirate fluid from

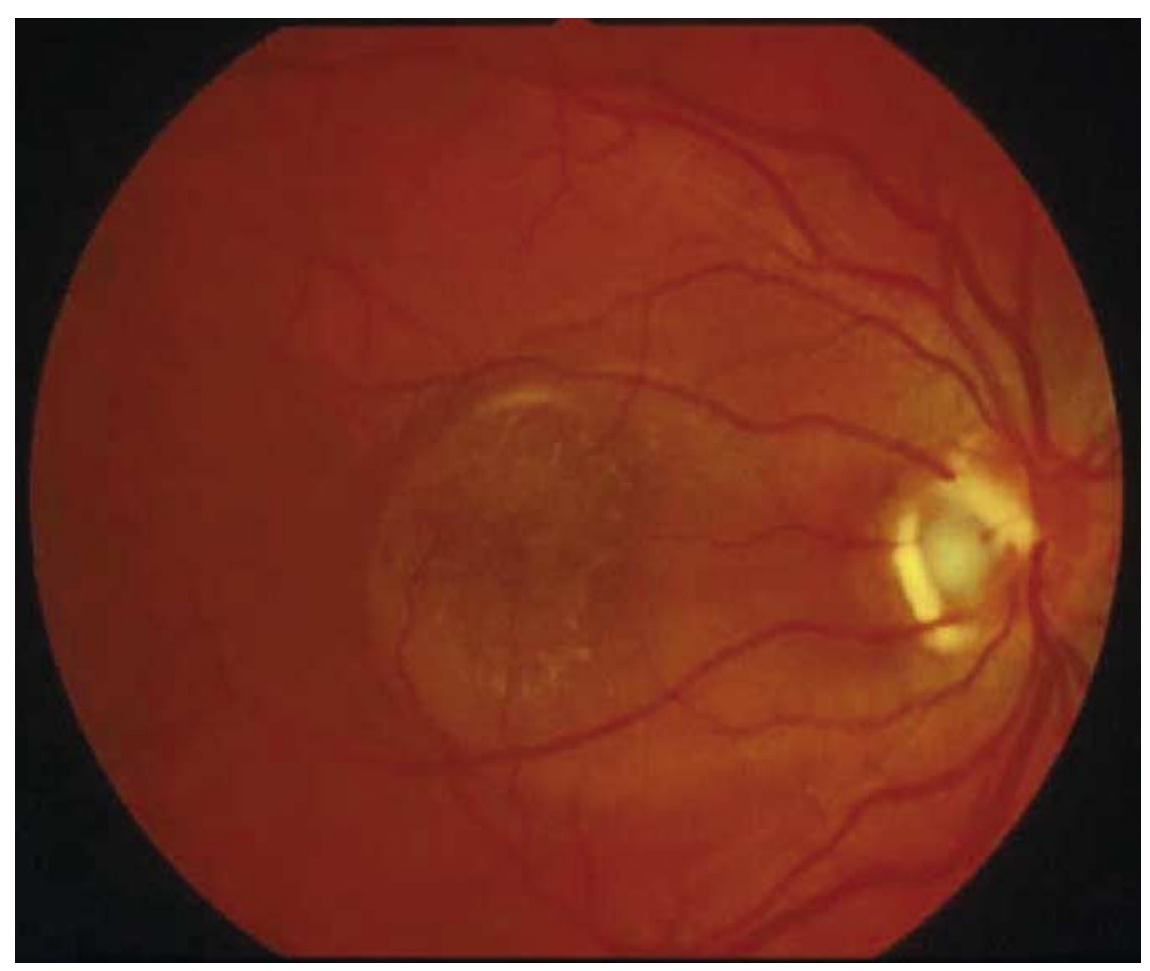

Figure 3 Right fundus of a 34-year-old man with a serous macular detachment and an optic disc pit. Visual acuity was reduced to $6 / 24$. 


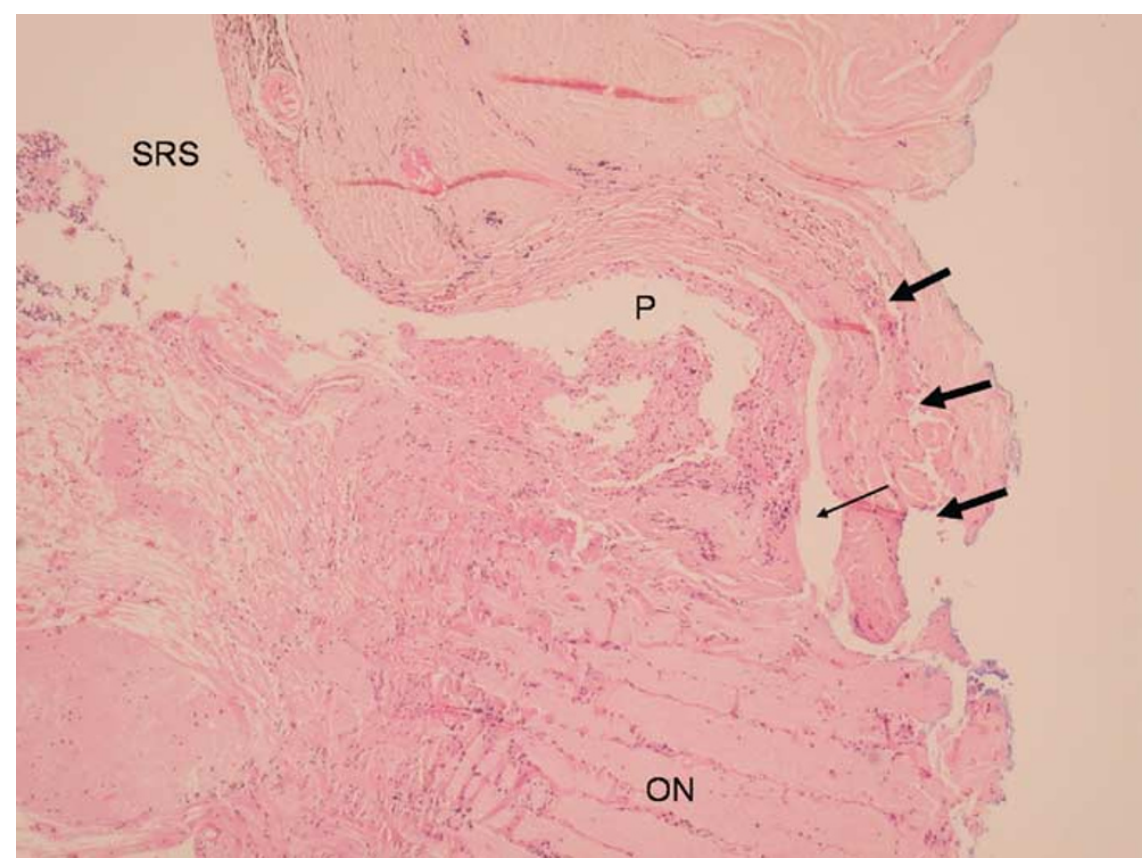

Figure 4 Section of optic nerve (ON) with optic disc pit $(\mathrm{P})$ connecting to the subretinal space (SRS). Pia-lined subarachnoid space (thick black arrows). Thin black arrow shows either artefactual split or extension of the subarachnoid space.

over the pit. The time taken for fluid to resorb may suggest fluid of high viscosity and of vitreous origin.

Whatever the source of fluid, it seems clear that the production of a permanent barrier between the pit and the macula is effective in allowing resolution of the macular detachment. There is mounting evidence that this is best achieved using intraocular gas tamponade, with or without vitrectomy, after laser photocoagulation to allow the generation of a firm chorioretinal adhesion.

\section{Radial optic neurotomy for central retinal vein occlusion}

Central retinal vein occlusion (CRVO) is a leading cause of visual loss with no widely accepted effective treatment. Panretinal photocoagulation is recommended ${ }^{50}$ for treatment of iris or angle neovascularisation in ischaemic (nonperfused) CRVO. Grid macular laser photocoagulation has been found to reduce angiographic macular oedema but does not improve visual acuity. ${ }^{51}$ Other treatments under investigation include laser-induced chorioretinal anastomosis, ${ }^{52}$ thrombolytic therapy, ${ }^{53-55}$ intravitreal triamcinolone, ${ }^{56,57}$ and external optic nerve decompression..$^{58-60}$

The pathogenesis of CRVO is not well understood. Histopathologic examination of enucleated eyes demonstrates thrombosis of the central retinal vein at the level of the lamina cribrosa, ${ }^{61}$ but it is not clear whether this is a primary or a secondary event. A nonperfused central vein occlusion may be due to compromised flow in the central retinal artery and vein. ${ }^{62}$ Risk factors for CRVO include hypertension, glaucoma, hypercholesterolaemia, diabetes, and hyperviscosity states.

Opremcak et $a l^{63}$ suggest that the anatomy of the scleral outlet (the space containing the cribriform plate, scleral canal, optic nerve, central retinal artery and vein) may play a role in the pathogenesis of CRVO.

Neurovascular compression is hypothesised to occur within this confined space analogous to a 'compartment syndrome' leading to compression of the lumen of the vein and occlusion of the central retinal vein. It is suggested that surgery to relax this space may relieve pressure on the central retinal vein, increasing venous blood outflow and allow clearing of venous thrombosis.

After studies in cadaver eyes, a procedure was devised that involves a pars plana vitrectomy and incision of the nasal portion of the optic nerve with a microvitreoretinal (MVR) blade to decompress the scleral outlet. The surgical site is carefully selected to avoid major branches of the retinal arterioles and venules and performed on the nasal side of the disc to reduce the risk to the macula nerve fibres. The incision is radial to the optic disc and parallel to the nerve fibres. The blade is directed posteriorly into the optic nerve cutting an equal portion of the cribriform plate and adjacent sclera and to a depth just beyond the widest portion of the diamond-shaped tip. The intraocular pressure is raised peroperatively to minimise any potential bleeding. 
In all, 11 patients with 'severe haemorrhagic' CRVO with initial visual acuity of 20/400 or worse were included in a pilot study. All patients had intraretinal haemorrhage and macular oedema. Out of 11, five were classified as perfused and six as indeterminate: four patients had iris neovascularisation and two had vessels in the angle. The average age was 60 years with a range of 35-86 years. The average duration of the CRVO prior to surgery was 4 months with a range of 1-7 months. There were no retinal or vitreous haemorrhages noted during or after the procedure. The average follow-up was 9 months. No complications were noted. All patients had improvement in the appearance of the fundus as documented by photography and fluorescein angiography. Postoperative visual acuities were equal or improved in $82 \%$ of patients. Eight of the patients (73\%) had rapid improvement of visual acuity with an average gain of five lines of vision. In all, $45 \%$ had vision better than or equal to 20/70. Two patients (18\%) achieved 20/ 40. Two patients lost one line of visual acuity. This compares to the Central Vein Occlusion Study (CVOS) that showed that patients who had poor visual acuity at the first visit $(<20 / 200)$, had an $80 \%$ chance of having a visual acuity less than $20 / 200$ at final visit, whether perfused or nonperfused initially. ${ }^{64}$

Lit $e t a l^{65}$ have developed a lancet with a sharp cutting edge and an opposing blunt edge and demonstrated histologically that a similar technique, which they call lamina puncture, is technically feasible, creating a perivascular space with minimal optic nerve fibre damage.

The apparently impressive results found by Opremcak et al have been challenged by several authors. Bynoe ${ }^{66}$ disagrees with the hypothesis and has reservations about the visual results questioning the reason for measuring Snellen acuity rather than the Early Treatment Diabetic Retinopathy Study (ETDRS) acuity used by the CVOS. He argues that it is possible for eyes reading only 20/400 Snellen or worse to read 20/200 on the ETDRS chart. The CVOS demonstrated that patients with intermediate initial acuity (20/50-20/200) showed a variable outcome, with $19 \%$ improving to better than $20 / 50$. If some of Opremcak et al's patients fell into the intermediate group, then the results would be similar to those expected from the natural history. Bynoe also disputes the assertion that there is no other effective treatment citing results from studies utilising external approaches to decompress the optic nerve $\mathrm{e}^{59,60,58}$ and tissue plasminogen activator, ${ }^{53-55}$ some of which showed similar results, although he acknowledges their complications.

Hayreh $^{67}$ challenges the claims made by Opremcak on several counts. He questions the validity of the 'compartment syndrome' hypothesis, stressing that even in conditions where there may be marked disc swelling,
CRVO rarely occurs. He doubts that decompression can reopen a thrombosed, occluded vein to establish or improve blood flow in it and claims that in the majority of CRVO eyes, the site of occlusion in the optic nerve is at a variable distance posterior to the lamina cribrosa, not at the lamina cribrosa. He also worries about the safety of the technique despite no complications being reported in this series. Potential complications include transection of the nerve fibre layer with consequent loss of visual field, damage to the Zinn-Haller artery, damage to the central retinal artery or vein and intraocular bleeding, retinal detachment, globe perforation, and neovascularisation. It is acknowledged that the circle of Zinn must be damaged in this procedure. ${ }^{68}$. Another criticism of this paper, and the CVOS, is the failure to differentiate adequately between ischaemic and nonischaemic vein occlusions, which have very different natural histories. Hayreh ${ }^{69}$ has shown in his natural history study of 144 patients with nonischaemic vein occlusion that $65 \%$ had a final acuity of $20 / 40$ or better.

Although Opremcak et $a l^{70}$ found no detrimental effect of the technique on visual fields, Williamson et $\mathrm{l}^{71}$ noted temporal segmental visual field loss in one of four patients who underwent radial optic neurotomy, suggesting damage to the nerve fibres. Samuel et al ${ }^{72}$ report a peripapillary retinal detachment extending from the neurotomy site. The retinal detachment spontaneously reattached over 12 days, with no recurrence, but the vision remained poor due to persistent macular oedema. In Weizer et al's $^{73}$ series of five patients, two patients developed neovascular complications: one developed choroidovitreal neovascularisation from the neurotomy site 3 months postoperatively; the other developed neovascularisation of the iris 2 weeks postoperatively. Both responded to panretinal photocoagulation. Peripapillary choroidal neovascularisation has been reported following optic neurotomy performed for the treatment of nonarteritic anterior ischaemic optic neuropathy. ${ }^{74}$

Guajardo et $\mathrm{al}^{75}$ have used the technique of radial optic neurotomy in a small series and have not been able to reproduce the results of Opremcak and coworkers. Weizer et $a l^{73}$ treated five patients with severe visual loss (6/200 or less) due to CRVO (one having a hemiretinal vein occlusion). Preoperatively, three (60\%) had an afferent pupillary defect and all had macular oedema. One was classified as perfused, one nonperfused, and three indeterminate. Best-corrected visual acuity improved in four patients (in two to 20/80) but was not statistically significant. Perfusion status did not improve postoperatively. Venous filling remained delayed in four cases. Macular oedema improved significantly in only one patient (hemiretinal vein occlusion). 
Garciia-Arumii et $a l^{76}$ treated 14 patients with nonischaemic CRVO and visual acuity of 20/125 or worse caused by macular oedema and haemorrhages. Best-corrected visual acuity improved in 57\%. Seven patients $(50 \%)$ had a final best-corrected acuity of $20 / 70$ or better. Clinical improvement of the macular oedema and haemorrhages was observed in all patients. New chorioretinal shunts developed in six patients $(43 \%)$ at the site of the radial optic neurotomy and these may explain the improved perfusion. The patients with collaterals in whom vision did not improve had subretinal macular haemorrhage and macular ischaemia.

Friedman ${ }^{77}$ reports two patients developing optociliary venous anastomosis after radial optic neurotomy for nonischaemic CRVO with improvement in vision and clinical appearance. Williamson et $a^{71}$ treated four patients with radial optic neurotomy in a pilot study of pars plana vitrectomy, intraocular gas, and radial neurotomy in ischaemic CRVO. Three of the four eyes developed blood vessels in the neurotomy site, two of whom showed a reduction in venous congestion.

The conclusions of the paper by Opremcak are that surgical decompression of CRVO via radial optic neurotomy is a technically feasible and initially safe procedure that is associated with rapid reperfusion of the retina and that resolution of the intraretinal haemorrhage, oedema, and ischaemia may improve the visual prognosis.

The premise that the optic nerve head is an anatomical bottleneck is not a logical one considering that the difference in diameter of the retrolaminar optic nerve can be explained physiologically by the additional myelin sheath. The rationale for decompressing a consequent 'compartment syndrome' is therefore difficult to understand. The explanation for the development of a hemiretinal vein occlusion, if this hypothesis is correct, is even more difficult to explain as compression would be expected to occlude both trunks of a dual-trunk retinal vein. $^{75}$

Opremcak claims that surgical relaxation of the scleral outlet is associated with dramatic and rapid clearing of the intraretinal haemorrhage and improved retinal blood flow in all patients but does not explain the mechanism for improvement in visual acuity. It is not clear whether it promoted resolution of macular oedema in the patients in the study. Williamson et $a l^{71}$ found that one of four eyes treated with vitrectomy without neurotomy also showed a reduction in venous congestion but without resolution of macular oedema. Vitrectomy alone in diabetics has been shown to improve retinal oxygenation and reduce both diabetic macular oedema and retinal neovascularisation. ${ }^{78}$ The two patients with worse visual acuity in Opremcak's study both had neovascularisation of the iris, and would reasonably be expected to have macular ischaemia. Even if it were possible, it is doubtful whether restoring blood flow to an ischaemic macula after any significant delay could have a beneficial effect on visual acuity.

Optic neurotomy may actually have an effect on retinal blood flow but by an unintended mechanism. Optociliary venous anastomoses (chorioretinal shunts or retinochoroidal collateral veins) have been demonstrated to improve retinal blood flow and are the deliberate endpoint for laser-induced chorioretinal venous anastomosis for treatment of nonischaemic CRVO. ${ }^{79}$ Collaterals may act protectively against the development of anterior segment neovascularisation ${ }^{80}$ and it is even feasible that they could reduce the proportion of patients converting from nonischaemic to ischaemic CRVO (34\% after 3 years in the CVOS).

\section{Conclusions}

One of the fundamental problems in assessing what some would see as a rather radical approach to the treatment of central retinal vein occlusion, is the disagreement about the natural history. The potential for serious complications is real, and the effectiveness and mode of action of treatment are still matters of conjecture. Clearer definitions of nonischaemic and ischaemic vein occlusions are required to elucidate the natural history of the separate groups before performing a randomised controlled study to decide whether there is a role for radial optic neurotomy in the treatment of CRVO.

\section{Acknowledgements}

We gratefully acknowledge the help of Tom Williamson and Katherine Haslam and funding from the University of Cambridge Retina Research Fund.

\section{References}

1 Wiethe T. Ein Fall von angeborener Difformitat der Sehnervenpapille. Arch Augenheilk 1882; 11: 14-19.

2 Apple DJ, Rabb MF. Developmental anomalies. In: Ocular Pathology: Clinical Applications and Self-Assessment. Mosby: St Louis, MO, 1998 pp 24-26.

3 Sadun AA. Optic Disc Pits and Associated Serous Macular Detachment. In: Ryan SJ (ed) Retina. Mosby: St Louis, MO, 2001 pp 1821-1827.

4 Brown GC, Shields JA, Goldberg RE. Congenital pits of the optic nerve head. II. Clinical studies in humans. Ophthalmology 1980; 87: 51-65.

5 Theodossiadis GP, Kollia AK, Theodossiadis PG. Cilioretinal arteries in conjunction with a pit of the optic disc. Ophthalmologica 1992; 204: 115-121. 
6 Kranenburg EW. Crater-like holes in the optic disc and central serous retinopathy. Arch Ophthalmol 1960; 64: 132/ 912-144/924.

7 Gass JD. Serous detachment of the macula. Secondary to congenital pit of the optic nervehead. Am J Ophthalmol 1969; 67: 821-841.

8 Sugar HS. Congenital pits in the optic disc and their equivalents (congenital colobomas and colobomalike excavations) associated with submacular fluid. Am J Ophthalmol 1967; 63: 298-307.

9 Slusher MM, Weaver Jr RG, Greven CM, Mundorf TK, Cashwell LF. The spectrum of cavitary optic disc anomalies in a family. Ophthalmology 1989; 96: 342-347.

10 Stefko ST, Campochiaro P, Wang P, Li Y, Zhu D, Traboulsi EI. Dominant inheritance of optic pits. Am J Ophthalmol 1997; 124: 112-113.

11 Brodsky MC. Congenital anomalies of the optic disc. In: Miller NR, Newman NJ, Hoyt WF (eds). Walsh $\mathcal{E}$ Hoyt's Clinical Neuro-Ophthalmology. Williams \& Wilkins: Baltimore, MD, 1998 pp 789-791.

12 Gass JD. Optic nerve diseases that may masquerade as macular diseases. In: A Stereoscopic Atlas of Macular Disease. Diagnosis and Treatment. Mosby: St Louis, MO, 1997, pp 976-983.

13 Lincoff H, Lopez R, Kreissig I, Yannuzzi L, Cox M, Burton T. Retinoschisis associated with optic nerve pits. Arch Ophthalmol 1988; 106: 61-67.

14 Theodossiadis GP, Panopoulos M, Kollia AK, Georgopoulos G. Long-term study of patients with congenital pit of the optic nerve and persistent macular detachment. Acta Ophthalmol (Copenh) 1992; 70: 495-505.

15 Theodossiadis GP, Ladas ID, Panagiotidis DN, Kollia AC, Voudouri AN, Theodossiadis PG. Fluorescein and indocyanine green angiographic findings in congenital optic disk pit associated with macular detachment. Retina 1999; 19: 6-11.

16 Sobol WM, Blodi CF, Folk JC, Weingeist TA. Long-term visual outcome in patients with optic nerve pit and serous retinal detachment of the macula. Ophthalmology 1990; 97: 1539-1542.

17 Sugar HS. An explanation for the acquired macular pathology associated with congenital pits of the optic disc. Am J Ophthalmol 1964; 57: 833-835.

18 Brockhurst RJ. Optic pits and posterior retinal detachment. Trans Am Ophthalmol Soc 1975; 73: 264-291.

19 Vogel MH, Wessing A. [Macula changes associated with pits in the optic disc (author's transl)]. Klin Monatsbl Augenheilkd 1974; 164: 90-97.

20 Postel EA, Pulido JS, McNamara JA, Johnson MW. The etiology and treatment of macular detachment associated with optic nerve pits and related anomalies. Trans Am Ophthalmol Soc 1998; 96: 73-88.

21 Bonnet M. Serous macular detachment associated with optic nerve pits. Graefes Arch Clin Exp Ophthalmol 1991; 229 : 526-532.

22 Billi B, Lesnoni G, Giuliano M, Rossi T, Stirpe M. Posttraumatic macular break associated to congenital optic disc pit and pre-existing sensory macular detachment. Int Ophthalmol 1996; 20: 269-272.

23 Brown GC, Shields JA, Patty BE, Goldberg RE. Congenital pits of the optic nerve head. I. Experimental studies in collie dogs. Arch Ophthalmol 1979; 97: 1341-1344.
24 Lincoff H, Kreissig I. Optical coherence tomography of pneumatic displacement of optic disc pit maculopathy. $\mathrm{Br} \mathrm{J}$ Ophthalmol 1998; 82: 367-372.

25 Irvine AR, Crawford JB, Sullivan JH. The pathogenesis of retinal detachment with morning glory disc and optic pit. Retina 1986; 6: 146-150.

26 Regenbogen L, Stein R, Lazar M. Macular and juxtapapillar serous retinal detachment associated with pit of optic disc. Ophthalmologica 1964; 148: 247-251.

27 Krivoy D, Gentile R, Liebmann JM, Stegman Z, Rosen R, Walsh JB et al. Imaging congenital optic disc pits and associated maculopathy using optical coherence tomography. Arch Ophthalmol 1996; 114: 165-170.

28 Kalina RE, Conrad WC. Letter: Intrathecal fluorescein for serous macular detachment. Arch Ophthalmol 1976; 94: 1421.

29 Savell J, Cook JR. Optic nerve colobomas of autosomaldominant heredity. Arch Ophthalmol 1976; 94: 395-400.

30 Tso MO, Shih CY, McLean IW. Is there a blood-brain barrier at the optic nerve head? Arch Ophthalmol 1975; 93: 815-825.

31 Montenegro M, Bonnet M. [Optic nerve pits: clinical and therapeutic review of 21 cases]. J Fr Ophtalmol 1989; 12: 411-419.

32 Galbraith JE, Sullivan JH. Decompression of the perioptic meninges for relief of papilledema. Am J Ophthalmol 1973; 76: 687-692.

33 Annesley W, Brown G, Bolling J, Goldberg R, Fischer D. Treatment of retinal detachment with congenital optic pit by krypton laser photocoagulation. Graefes Arch Clin Exp Ophthalmol 1987; 225: 311-314.

34 Cox MS, Witherspoon CD, Morris RE, Flynn HW. Evolving techniques in the treatment of macular detachment caused by optic nerve pits. Ophthalmology 1988; 95: 889-896.

35 Monin C, Le Guen Y, Morel C, Haut J. [Treatment of coloboma pits of the optic nerve complicated by serous detachment of the neuroepithelium]. J Fr Ophtalmol 1994; 17: 574-579.

36 Yanyali A, Bonnet M. [Treatment of macular detachment complicating optic disk coloboma pits. Long-term results of the photocoagulation-gas combination]. J Fr Ophtalmol 1993; 16: 523-531.

37 Alexander TA, Billson FA. Vitrectomy and photocoagulation in the management of serous detachment associated with optic nerve pits. Aust J Ophthalmol 1984; 12: 139-142.

38 Schatz H, McDonald HR. Treatment of sensory retinal detachment associated with optic nerve pit or coloboma. Ophthalmology 1988; 95: 178-186.

39 Snead MP, James N, Jacobs PM. Vitrectomy, argon laser, and gas tamponade for serous retinal detachment associated with an optic disc pit: a case report. Br J Ophthalmol 1991; 75: 381-382.

40 Lee KJ, Peyman GA. Surgical management of retinal detachment associated with optic nerve pit. Int Ophthalmol 1993; 17: 105-107.

41 Taiel-Sartral M, Mimoun G, Glacet-Bernard A, Delayre T, Coscas G. [Vitrectomy-laser-gas for treating optic disk pits complicated by serous macular detachment]. J Fr Ophtalmol 1996; 19: 603-609.

42 Konno S, Akiba J, Sato E, Kuriyama S, Yoshida A. OCT in successful surgery of retinal detachment associated with optic nerve head pit. Ophthalmic Surg Lasers 2000; 31: 236-239. 
43 Bartz-Schmidt KU, Heimann K, Esser P. Vitrectomy for macular detachment associated with optic nerve pits. Int Ophthalmol 1995; 19: 323-329.

44 Hoerauf H, Schmidt-Erfurth U, Laqua H. [Follow-up of vitrectomy for central retinal detachment and optic disk pit]. Klin Monatsbl Augenheilkd 1996; 209: 238-243.

45 Gandorfer A, Kampik A. [Role of vitreoretinal interface in the pathogenesis and therapy of macular disease associated with optic pits]. Ophthalmologe 2000; 97: 276-279.

46 Gotzaridis EV. Perifoveal traction retinal detachment following successful optic disc pit surgery. Ophthalmic Surg Lasers 2002; 33: 243-245.

47 Rosenthal G, Bartz-Schmidt KU, Walter P, Heimann K. Autologous platelet treatment for optic disc pit associated with persistent macular detachment. Graefes Arch Clin Exp Ophthalmol 1998; 236: 151-153.

48 Theodossiadis GP. Treatment of maculopathy associated with optic disk pit by sponge explant. Am J Ophthalmol 1996; 121: 630-637.

49 Ferry AP. Macular detachment associated with congenital pit of the optic nervehead. Pathologic findings in two cases simulating malignant melanoma of the choroid. Arch Ophthalmol 1963; 70: 346-357.

50 The Central Vein Occlusion Study Group N. A randomized clinical trial of early panretinal photocoagulation for ischemic central vein occlusion report. Ophthalmology 1995; 102: $1434-1444$.

51 The Central Vein Occlusion Study Group M. Evaluation of grid pattern photocoagulation for macular edema in central vein occlusion report. Ophthalmology 1995; 102: 1425-1433.

52 McAllister IL, Douglas JP, Constable IJ, Yu DY. Laserinduced chorioretinal venous anastomosis for nonischemic central retinal vein occlusion: evaluation of the complications and their risk factors. Am J Ophthalmol 1998; 126: 219-229.

53 Elman MJ. Thrombolytic therapy for central retinal vein occlusion: results of a pilot study. Trans Am Ophthalmol Soc 1996; 94: 471-504.

54 Lahey JM, Fong DS, Kearney J. Intravitreal tissue plasminogen activator for acute central retinal vein occlusion. Ophthalmic Surg Lasers 1999; 30: 427-434.

55 Weiss JN, Bynoe LA. Injection of tissue plasminogen activator into a branch retinal vein in eyes with central retinal vein occlusion. Ophthalmology 2001; 108: 2249-2257.

56 Greenberg PB, Martidis A, Rogers AH, Duker JS, Reichel E. Intravitreal triamcinolone acetonide for macular oedema due to central retinal vein occlusion. Br J Ophthalmol 2002; 86: $247-248$.

57 Ip M, Kahana A, Altaweel M. Treatment of central retinal vein occlusion with triamcinolone acetonide: an optical coherence tomography study. Semin Ophthalmol 2003; 18: 67-73.

58 Dev S, Buckley EG. Optic nerve sheath decompression for progressive central retinal vein occlusion. Ophthalmic Surg Lasers 1999; 30: 181-184.

59 Vasco-Posada J. Modification of the circulation in the posterior pole of the eye. Ann Ophthalmol 1972; 4: 48-59.

60 Arciniegas A. Treatment of the occlusion of the central retinal vein by section of the posterior ring. Ann Ophthalmol 1984; 16: 1081-1086.

61 Green WR, Chan CC, Hutchins GM, Terry JM. Central retinal vein occlusion: a prospective histopathologic study of 29 eyes in 28 cases. Trans Am Ophthalmol Soc 1981; 79: $371-422$.

62 Hayreh SS. Pathogenesis of occlusion of the central retinal vessels. Am J Ophthalmol 1971; 72: 998-1011.

63 Opremcak EM, Bruce RA, Lomeo MD, Ridenour CD, Letson AD, Rehmar AJ. Radial optic neurotomy for central retinal vein occlusion: a retrospective pilot study of 11 consecutive cases. Retina 2001; 21: 408-415.

64 The Central Vein Occlusion Study Group. Natural history and clinical management of central retinal vein occlusion. Arch Ophthalmol 1997; 115: 486-491.

65 Lit ES, Tsilimbaris M, Gotzaridis E, D'Amico DJ. Lamina puncture: pars plana optic disc surgery for central retinal vein occlusion. Arch Ophthalmol 2002; 120: 495-499.

66 Bynoe LA. Radial optic neurotomy for central retinal vein obstruction. Retina 2002; 22: 379-380.

67 Hayreh SS. Radial optic neurotomy for central retinal vein occlusion. Retina 2002; 22: 827.

68 Opremcak EM, Bruce RA, Lomeo MD, Ridenour CD, Letson AD, Rehmar AJ. Radial optic neurotomy for central retinal vein occlusion: reply. Retina 2002; 22: 377-379.

69 Hayreh SS. Retinal vein occlusion. Indian J Ophthalmol 1994; 42: 109-132.

70 Opremcak EM, Bruce RA, Lomeo MD, Ridenour CD, Letson $\mathrm{AD}$, Rehmar AJ. Radial optic neurotomy for central retinal vein occlusion: reply. Retina 2002; 22: 380-381.

71 Williamson TH, Poon W, Whitefield L, Strothoudis N, Jaycock P. A pilot study of pars plana vitrectomy, intraocular gas, and radial neurotomy in ischaemic central retinal vein occlusion. Br J Ophthalmol 2003; 87: 1126-1129.

72 Samuel MA, Desai UR, Gandolfo CB. Peripapillary retinal detachment after radial optic neurotomy for central retinal vein occlusion. Retina 2003; 23: 580-583.

73 Weizer JS, Stinnett SS, Fekrat S. Radial optic neurotomy as treatment for central retinal vein occlusion. Am J Ophthalmol 2003; 136: 814-819.

74 Soheilian M, Koochek A, Yazdani S, Peyman GA. Transvitreal optic neurotomy for nonarteritic anterior ischemic optic neuropathy. Retina 2003; 23: 692-697.

75 Guajardo LL, de la Huerga AM, Sandomingo AF, Maresca FA. Radial optic neurotomy as a treatment of central vein occlusion: neurotomy in central vein occlusion. Retina 2003; 23: 890.

76 Garciia-Arumii J, Boixadera A, Martinez-Castillo V, Castillo R, Dou A, Corcostegui B. Chorioretinal anastomosis after radial optic neurotomy for central retinal vein occlusion. Arch Ophthalmol 2003; 121: 1385-1391.

77 Friedman SM. Optociliary venous anastomosis after radial optic neurotomy for central retinal vein occlusion. Ophthalmic Surg Lasers Imaging 2003; 34: 315-317.

78 Stefansson E. The therapeutic effects of retinal laser treatment and vitrectomy. A theory based on oxygen and vascular physiology. Acta Ophthalmol Scand 2001; 79: 435-440.

79 McAllister IL, Constable IJ. Laser-induced chorioretinal venous anastomosis for treatment of nonischemic central retinal vein occlusion. Arch Ophthalmol 1995; 113: 456-462.

80 Fuller JJ, Mason III JO, White Jr MF, McGwin Jr G, Emond TL, Feist RM. Retinochoroidal collateral veins protect against anterior segment neovascularization after central retinal vein occlusion. Arch Ophthalmol 2003; 121: 332-336. 